\title{
In Memoriam: Edmund J. Bini, MD, MPH (1967-2010)
}

\author{
Norbert Bräu
}

Published online: 10 April 2010

(C) Springer Science+Business Media, LLC 2010

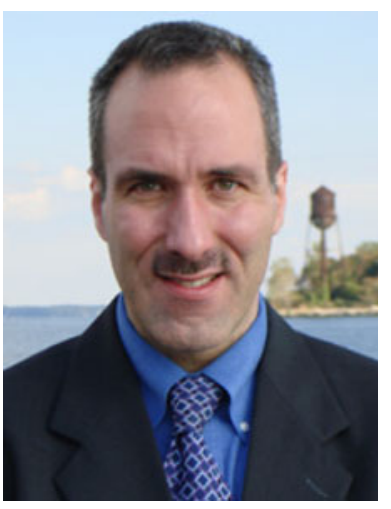

Edmund J. Bini, MD, MPH

Digestive Diseases and Sciences has lost a member of its editorial family, with the untimely death of associate editor Edmund J. Bini, MD, MPH on March 13, 2010. Dr. Bini was an Associate Professor of Medicine and the Director of Gastroenterology and Hepatology Research in the Division of Gastroenterology at New York University School of Medicine. He was also Chief of Gastroenterology and Hepatology at the Manhattan campus of the VA New York Harbor Health Care System. Dr. Bini graduated summa cum laude from Fordham University and received his medical degree at New York University and his master of public health at Johns Hopkins University. He completed residency training in internal medicine at the Mount Sinai Medical Center, and fellowship in gastroenterology and hepatology at New York University Medical Center. In

N. Bräu $(\bowtie)$

Bronx Veterans Affairs Medical Center \& Mount Sinai School of Medicine, New York, NY, USA

e-mail: Norbert.Brau@va.gov addition to his service as associate editor for Digestive Diseases and Sciences, he served on the editorial boards of Gastroenterology and Gastrointestinal Endoscopy as well as on the Hepatitis C Treatment Advisory Committee of the US Department of Veterans Affairs.

Dr. Bini had a great passion for clinical research on the natural history and therapy of chronic hepatitis $\mathrm{C}$, and he was a prodigious writer who authored close to 100 peerreviewed publications. His enthusiasm for clinical investigation was contagious, and scores of gastroenterology fellows, medical residents, and medical students were mentored by him in the performance of clinical studies that utilized his unique prospective database of over 1,200 patients with chronic hepatitis C. Many of these young investigators owe their initial first-author paper to Dr. Bini's stewardship. He had boundless energy and an insightful vision for research.

Dr. Bini was also an educator par excellence and quite active in the New York Society for Gastrointestinal Endoscopy. He served as a co-director of the annual postgraduate course, member of the Executive Council, and vice president. He also was a frequent lecturer, both locally in the New York City area, as well as nationally. In addition, Ed was devoted to his patients and highly rated as an outstanding practitioner of gastroenterology and hepatology.

Dr. Bini will be sorely missed by his patients, students, colleagues, and friends. The members of the editorial team at Digestive Diseases and Sciences, especially Dr. Emmet Keeffe, the editor-in-chief, and the associate editors extend their most sincere condolences to Ed's widow, Dr. Rosa Cipollone, who practices internal medicine in New York. The photo shows Ed how he will be remembered-his face both sincere and smiling, never hiding his great sense of humor. 